\title{
Two-dimensional resistivity structure of Unzen Volcano revealed by AMT and MT surveys
}

\author{
Shogo Komori ${ }^{1 *}$, Tsuneomi Kagiyama ${ }^{2}$, Mitsuru Utsugi ${ }^{2}$, Hiroyuki Inoue $^{2}$, and Itsuo Azuhata ${ }^{2 \dagger}$ \\ ${ }^{1}$ Aso Volcanological Laboratory, Kyoto University, 5280 Kawayo, Minamiaso, Kumamoto 869-1404, Japan \\ ${ }^{2}$ Graduate School of Science, Kyoto University, Kitashirakawa-Oiwake-cho, Sakyo-ku, Kyoto 606-8502, Japan
}

(Received November 17, 2011; Revised August 14, 2012; Accepted October 26, 2012; Online published August 23, 2013)

\begin{abstract}
AMT and MT surveys were conducted to investigate at high resolution the spatial resistivity structure of Unzen volcano, with consideration given to understanding its regional dimensionality. Our phase tensor analysis supports the conclusion that the resistivity structure is two-dimensional, with the strike in the E-W direction. Two-dimensional inversions suggest that Unzen volcano is likely to comprise 4 layers: a high resistivity surface (greater than $1000 \Omega \mathrm{m}$ ), an intermediate second layer (20 to several hundreds of $\Omega \mathrm{m}$ ), a low resistivity third layer (less than $20 \Omega \mathrm{m}$ ), and a relatively high resistivity basement. We assume the upper-most high resistivity layer consists of undersaturated lava and pyroclastic flow deposits. The second and third layers are likely to be water-saturated and form an aquifer that seems to correlate well with the emergence of groundwater discharge at the surface. In deeper areas beneath the summit, a region with a resistivity of $20-80 \Omega \mathrm{m}$ is surrounded by areas of extremely low resistivity (less than $3 \Omega \mathrm{m}$ ); this structural features in Unzen volcano was first identified in this study, but is typical of the resistivity structure observed in active volcanoes. Interpreting the results of well logs and geodetic studies of Unzen volcano in light of the findings of the present study and the resistivity structure of other active volcanoes, we suggest that Unzen volcano possesses a hydrothermal system of high-temperature fluids beneath its edifice; this hydrothermal system may play a non-negligible role in controlling heat and mass transfer in the magmatic system of Unzen volcano.
\end{abstract}

Key words: Unzen volcano, resistivity structure, Unzen graben, aquifer, volcanic fluids, hydrothermal alteration, conduit.

\section{Introduction}

Unzen volcano is a group of lava domes located on the Shimabara Peninsula, SW Japan (Hoshizumi et al., 1999). The Shimabara Peninsula is situated in a volcanotectonic depression (Ohta, 1973; Chida, 1979). N-S extension has formed Unzen graben defined by the E-W trending faults, shown by the heavy lines in Fig. 1. The present center of volcanic activity is located in the middle of Unzen graben, Mt. Fugen-dake and Mt. Heisei-shin-zan. The resistivity characteristics of the Shimabara Peninsula have been investigated extensively using electromagnetic methods (e.g., airborne electromagnetic method (Mogi et al., 1995); VLF-, ELF-, and ULF-MT (Kagiyama et al., 1999); TDEM (Kanda, 1997; Srigutomo et al., 2008)). Srigutomo et al. (2008) found two high conductance areas at the western and eastern part of Shimabara Peninsula. By comparing their results with seismic activity (Umakoshi et al., 1994) and soil $\mathrm{CO}_{2}$ emissions (Takahashi et al., 2004) in the area,

*Now at Institute of Earth Sciences, Academia Sinica, 128 Academia Road, Section 2, Nankang, Taipei 115, Taiwan, R.O.C.

${ }^{\dagger}$ Now at Nagano Prefecture Matsumoto Regional Office, 1020 Shimadachi Matsumoto, Nagano Prefecture 390-0852, Japan.

Copyright (c) The Society of Geomagnetism and Earth, Planetary and Space Sciences (SGEPSS); The Seismological Society of Japan; The Volcanological Society of Japan; The Geodetic Society of Japan; The Japanese Society for Planetary Sciences; TERRAPUB.

doi:10.5047/eps.2012.10.005 the authors inferred that their observations of high conductance were due to the vigorous release of volcanic gas from magma.

Regarding the summit area, the presence of the active hydrothermal system was inferred at the surface, from the high SP (self-potential) anomaly (Hashimoto and Tanaka, 1995; Hashimoto, 1997) and the low resistivity surface (Kagiyama et al., 1999). These facts expected that the magmatic activity might extend the low resistivity region from the deeper part to the surface, making high conductance at the area; such resistivity feature, however, was not detected by Srigutomo et al. (2008). In the authors' work, the detailed resistivity structure could not be obtained because of the one-dimensional analysis and the insufficient observation points around the summit area. Therefore, the geometry and condition of the hydrothermal system beneath Unzen volcano have remained unknown. The present study aims to determine the regional dimensionality of the system and provide a high resolution understanding of the resistivity structure of Unzen volcano (Mt. Fugen-dake, shown in Fig. 1) and the underlying hydrothermal system.

\section{AMT and MT Surveys}

\subsection{Data acquisition and processing}

Magneto-tellurics (MT) is a geoelectrical sounding method used for estimating resistivity structure on the basis of electromagnetic induction (e.g., Cagniard, 1953; Vozoff, 1991; Simpson and Bahr, 2005). For the present study, 


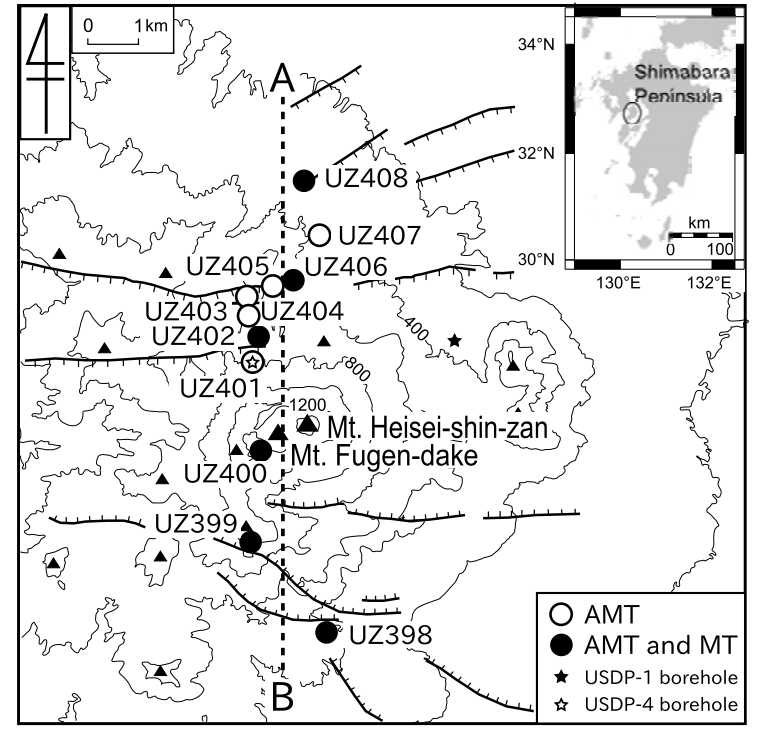

Fig. 1. Location of Unzen volcano in Shimabara peninsula, SW Japan. Open circles represent the observation points of AMT. Solid circles represent the observation points of AMT and MT. Line A-B, heavy line, and stars represents the projection plane of the resistivity structure, the faults, and the boreholes, respectively. Small lines on the heavy line represent the dip of the fault.

AMT (Audio Magneto-tellurics) and MT surveys were conducted in November 2008, and July and August 2009 on the Unzen volcanic massif, using Phoenix Geophysics MTU5 system. The observation points, shown in Fig. 1, were configured in a N-S direction across the summit of Unzen volcano. Four $\mathrm{Pb}-\mathrm{PbCl}_{2}$ electrodes were used for measuring two orthogonal components of electric fields (N-S and E-W directions), and one additional electrode was used for grounding. Three orthogonal components of magnetic field (N-S, E-W, and vertical directions) were measured using three induction coils, which consist of a coil of copper wire wound on a core with high magnetic permeability. Data were collected in the frequency range between $1 \mathrm{~Hz}$ and $10 \mathrm{kHz}$. For the relatively high frequency range between $100 \mathrm{~Hz}$ and $10 \mathrm{kHz}$, AMT induction coils were used, and each observation point continued data acquisition for four hours. For the relatively low frequency range between 1 $\mathrm{Hz}$ and $100 \mathrm{~Hz}$, MT induction coils were used, and each observation point continued data acquisition for one week. To remove contamination in the data due to local noise, we applied Gamble et al.'s (1979) remote reference processing method using geomagnetic data from Sawauchi (1000 $\mathrm{km}$ from Unzen). For the data obtained with the AMT induction coils, we performed mutual referencing within the survey area.

\subsection{Dimensionality and strike estimation}

To estimate the dimension of the structure of Unzen volcano, impedance phase tensors and skew angles $(\beta)$ were calculated using the method of Caldwell et al. (2004); this method has the merit of removing distortion from the original impedances due to near surface anomalies. Figure 2(a) shows the impedance phase tensors, skew angles, and induction arrows for representative frequencies. The error of the skew angle is less than 0.1 degree for a frequency of (a)

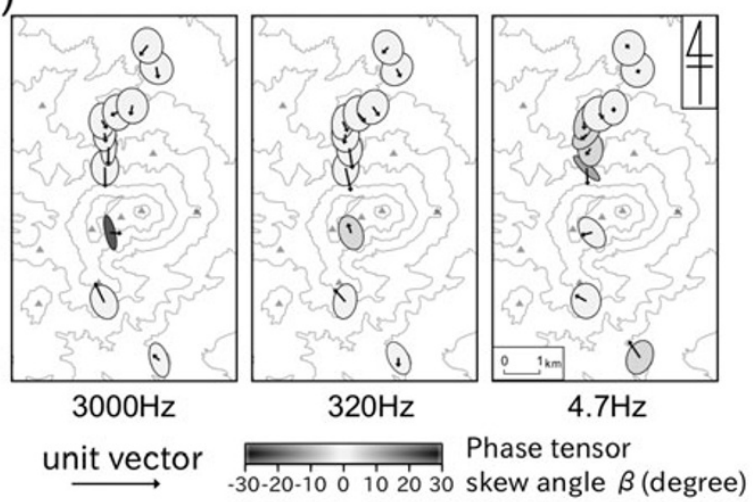

(b)
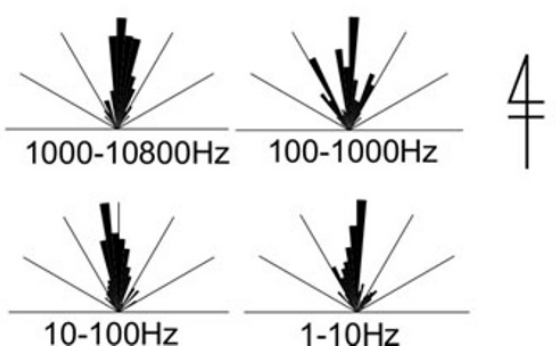

Fig. 2. Data for dimensionality and strike estimation. (a) Impedance phase tensors, skew angles $\beta$, and induction arrows for representative frequencies. (b) Rose diagrams of tensor axes.

$100-10800 \mathrm{~Hz}$, and several degrees for a frequency of $1-$ $100 \mathrm{~Hz}$. The skew angles are relatively large for the frequencies higher than $3 \mathrm{kHz}$ near the summit of Unzen. This suggests that the near surface of Unzen volcano has significant inhomogeneity. On the other hand, the major axes of the impedance phase tensors in Fig. 2(a) are oriented roughly to the same direction. Further, the rose histograms of the major axes of the impedance phase tensors, shown in Fig. 2(b), mean that most of the axes for the whole frequencies are oriented to the same direction. These suggest that it would be reasonable to assume a regional 2-D structure with near surface inhomogeneity in the summit area. Therefore, in this study, we attempted to estimate the resistivity structure by assuming regional 2-D structure.

Secondly, the regional strike of Unzen volcano was estimated using the histograms of the major axes of the impedance phase tensors. The error of the axes is less than a few degrees for a frequency of $10-10800 \mathrm{~Hz}$, and about several tens degrees for a frequency of $1-10 \mathrm{~Hz}$. The modes of the regional strikes were $\mathrm{N} 3.6^{\circ} \mathrm{E}$ for over $1000 \mathrm{~Hz}, \mathrm{~N} 2.4^{\circ} \mathrm{W}$ for $100-1000 \mathrm{~Hz}, \mathrm{~N} 0.1^{\circ} \mathrm{E}$ for $10-100 \mathrm{~Hz}$, and $\mathrm{N} 1.5^{\circ} \mathrm{W}$ for $1-10 \mathrm{~Hz}$ respectively. Thus, the averaged mode of the regional strikes for whole frequencies was either $\mathrm{N} 0.1^{\circ} \mathrm{E}$ or $\mathrm{N} 89.9^{\circ} \mathrm{E}$, noting that regional strike obtained from phase tensor ellipses has $90^{\circ}$ ambiguity. In this study area, E-W striking faults are predominant, due to N-S tensional stress (Hoshizumi et al., 1999). According geological information obtained from boreholes, the basement has continuity in the E-W direction, deepening towards the center of the Unzen graben (Hoshizumi et al., 2002). Taken together, these facts suggest the regional geology is discontinuous in the N-S di- 


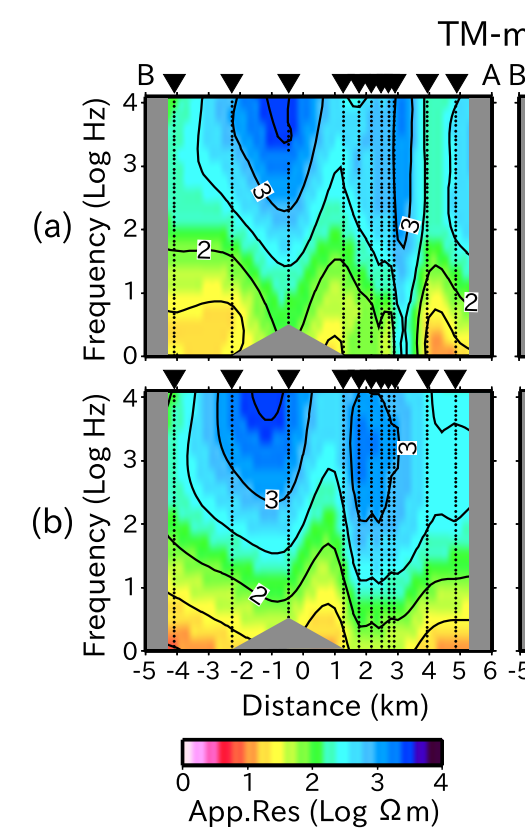

M-mode

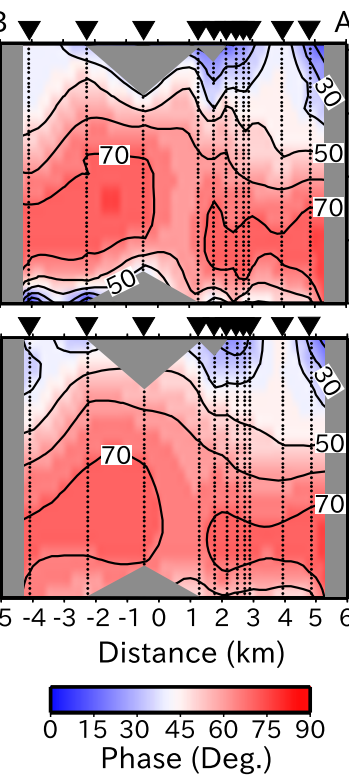

TE-mode

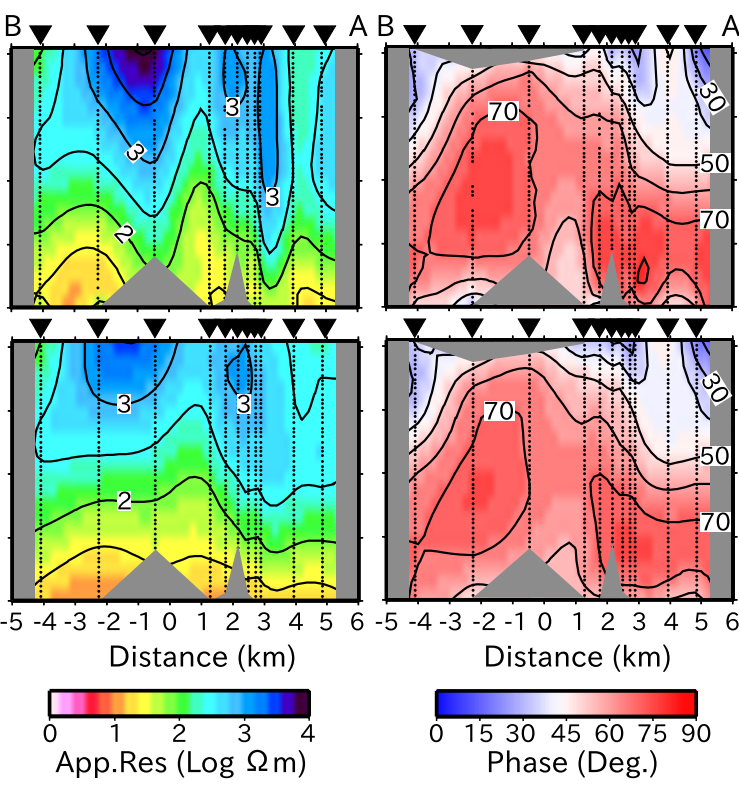

Fig. 3. Pseudosection of apparent resistivity and phase for both TM- and TE-modes. For each mode, (a) and (b) show observed and calculated pseudosections, respectively.

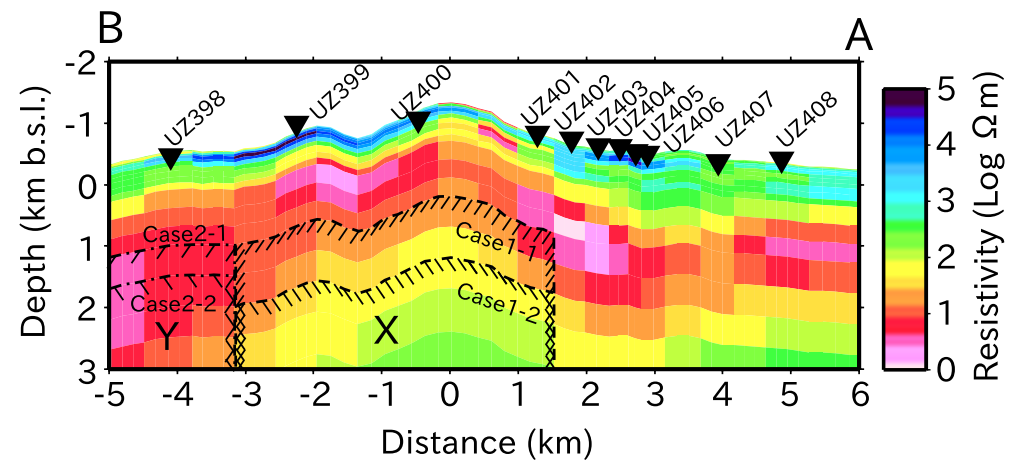

Fig. 4. Best fit model obtained from 2-D analysis. Solid inverted triangles and line represent observation points and trajectory of borehole USDP-4. X and $\mathrm{Y}$ represents the regions used for the sensitivity tests.

rection. Induction arrows are also oriented roughly in N-S directions for most frequencies. Therefore, regional strike is estimated at $\mathrm{N} 89.9^{\circ} \mathrm{E}$, that is, almost in the $\mathrm{E}-\mathrm{W}$ direction. Accordingly, the impedance tensors were rotated to correspond with a 2-D strike oriented to N89.9; after which, distortion analysis by the method of Bibby et al. (2005) was performed. This procedure estimates the distortion tensor, produced by the surface heterogeneity, considering the ellipticity of the phase tensor and $\beta$ angle. The effect of the distortion was removed from the rotated impedance tensor by multiplying the inversion matrix of the distortion tensor and the impedance tensor.

Figure 3 shows the pseudosection of apparent resistivity and phase of both TM- and TE-modes calculated from impedance tensors obtained by the process described above. Apparent resistivity and phase of TM mode are calculated, using electric fields perpendicular to the strike and magnetic fields parallel to the strike. TE-mode treats electric and magnetic fields in an opposite manner. For both modes, apparent resistivities comprehensively have the high values at the high frequencies, and decrease as frequencies decrease.
Phases have the low values below 45 degrees at the high frequencies between $10 \mathrm{kHz}$ and several $\mathrm{kHz}$, except for both modes of UZ398 and TE mode of UZ407. They increase as frequencies decrease over a range of $10 \mathrm{kHz}$ to $10 \mathrm{~Hz}$, and begin to decrease from around $10 \mathrm{~Hz}$. These features suggest that low resistivity layer is present between relatively higher resistivity layers.

TM modes of UZ402, 403, 404, 405, and 406 have almost the same phase characteristics as those reported in the above, with the exception of the apparent resistivities of UZ402 and 403, which are shifted slightly lower than the other observation points. In fact, UZ402 and UZ403 are located at the by precipitous cliffs. We attribute these shifts to the location of the transects near precipitous cliffs, as it is known that steep topographical changes can influence MT observations (e.g., Wannamaker et al., 1986; Jiracek, 1990). $2.3 \quad$ 2-D analysis

2-D resistivity structure analysis was performed using an inversion code developed by Ogawa and Uchida (1996). This code performs smoothness-constrained 2-D inversion based on the ABIC minimization method. In this inversion 
(a)
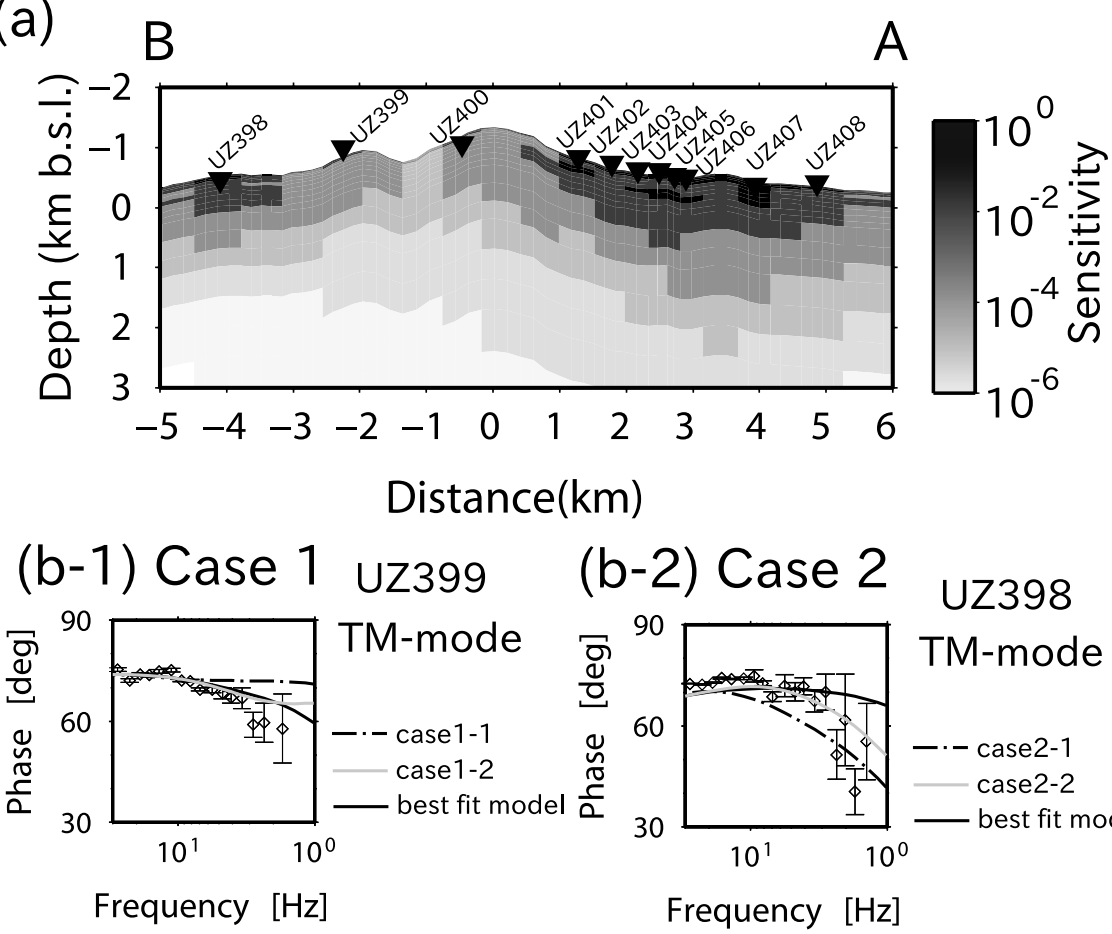

(b-2) Case 2

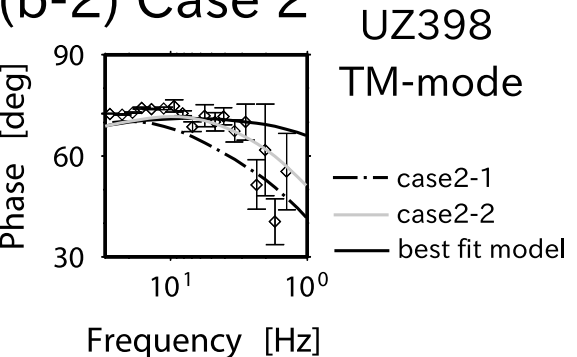

Fig. 5. Sensitivity tests. (a) Result of linear sensitivity analysis. (b) Sensitivities of TM phase at UZ399 and UZ400 by further sensitivity analysis for each cases.

scheme, trade-off parameters between data misfit, model roughness and static shift are estimated so as to minimize the misfit functional, assuming that static shifts have Gaussian distributions. In this study, both TM-mode and TEmode data were used for 2-D analysis. Minimum error floors for apparent resistivity and phase were set to be $5 \%$ and 1.4 degrees, respectively. Resistivity structure was projected to the N-S direction shown by Line A-B in Fig. 1, which is perpendicular to the strike and representative topography of the observation points. Calculation was started using an initial model with a uniform resistivity of $100 \Omega \mathrm{m}$. Figure 4 shows the best fit model obtained after achieving 67 iterations. RMS misfit was 1.24.

The pseudosection calculated from the best fit model is shown in Fig. 3. The inferred model is considered to reproduce most of the apparent resistivity and phase distributions. The discontinuity of phase between UZ406 and UZ407 at high frequencies is explained by shallowlyemplaced uniform resistivity blocks below UZ407 with a thickness of several hundred meters. The discontinuity between UZ398 and UZ399 is explained similarly by the inclusion of shallow blocks of uniform resistivity. In addition, TM-mode apparent resistivities are shifted to higher values at UZ402 and UZ403 as a correction of the static shift by the inversion process.

\subsection{Sensitivity tests}

Before making any interpretations on the basis of our analyses, we performed a series of tests to examine the sensitivity of the model. The tests performed are described in the following paragraphs.

2.4.1 linear sensitivity analysis Linear sensitivity analysis based on the method of Schwalenberg et al. (2002) was performed. According to those authors, model sensi- tivity can be described as:

$$
S_{j}=\frac{1}{\Delta_{j}} \sum_{i}^{N}\left\|\frac{1}{\sigma_{i}} \frac{\partial f_{i}(\mathbf{m})}{\partial \mathbf{m}_{\mathbf{j}}}\right\|
$$

Where, $S_{j}$ is the sensitivity of the respective grid element $j, \Delta_{j}$ is the size of the grid element $j, f_{i}(\mathbf{m})$ is the forward solution of model $\mathbf{m}, m_{j}$ is the resistivity change of the grid element $j, \sigma_{i}$ is the standard deviation of the data, and $N$ is the number of elements $(N=$ number of observation sites $\times$ number of frequency $x$ data types). This equation states that model resolution is the sum of the gradient of forward solution to the resistivity change of a given grid element, which is normalized by the standard deviation of the data, and weighted by the size of each grid element. Data and forward solutions include 4 types: apparent resistivities and phases of the TE- and TM-modes.

Figure 5(a) shows the model sensitivity obtained by the above method. The sensitivity calculations show that sensitivity decreases with depth, corresponding to the limit of the sounding frequency. In the northern shallow part of Unzen volcano, high sensitivities are obtained; on the other hand, relatively low sensitivities are found in the southern shallow part. These low sensitivities are attributed to sparse observation points in the southern part. Furthermore, the southern area shows very low sensitivities (less than $10^{-5}$ ) at deeper depths. This is because of few available data and the large errors of data with low frequency ranges between 1 and $10 \mathrm{~Hz}$. In fact, there are many electric power lines in the whole area of the volcano, and many buildings are also present on the foot of the volcano. These factors introduce noise into the data, and we therefore assume that data taken at frequencies below $10 \mathrm{~Hz}$ were contaminated despite the 

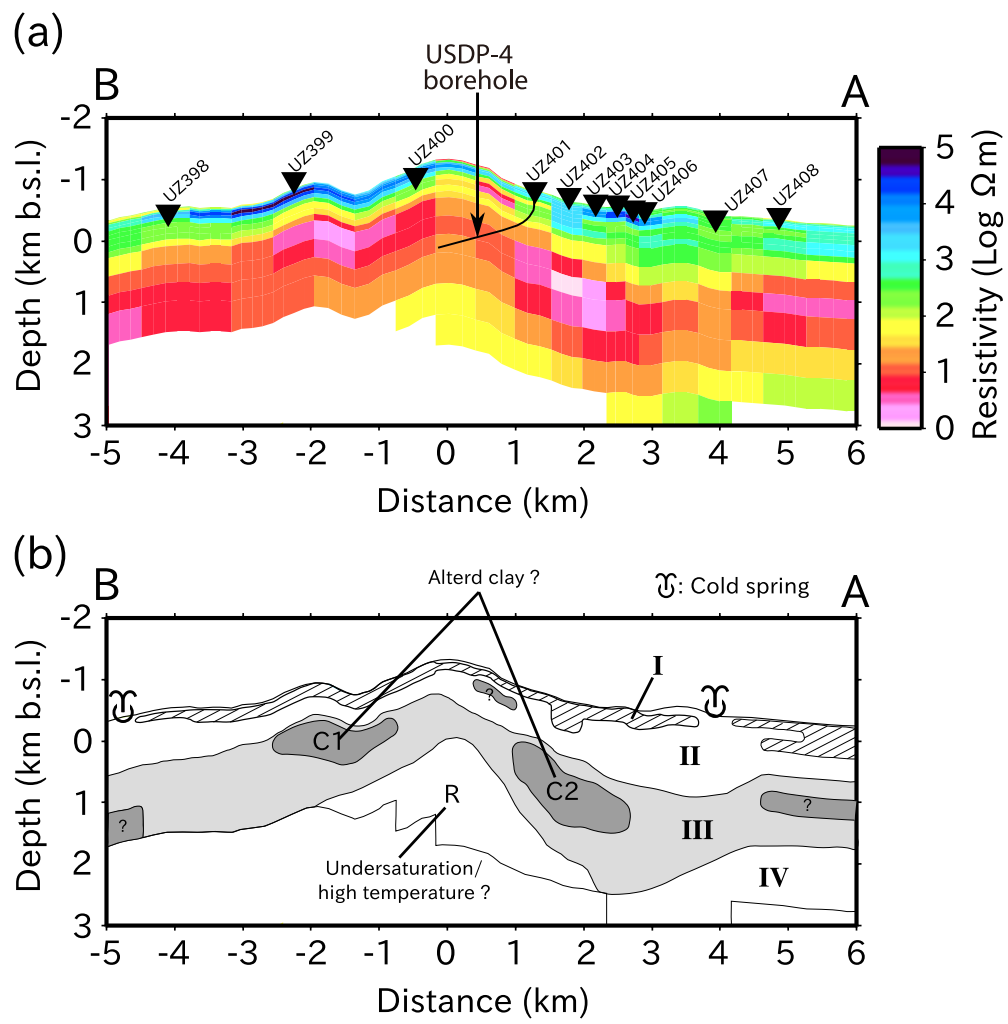

Fig. 6. (a) Resistivity structure after removing no sensitivity part. A heavy line represents the borehole USDP-4 by conduit drilling. (b) Interpretation of the resistivity structure. The high resistivity surface (greater than $1000 \Omega \mathrm{m}$ ) is shown by the shaded portion. The low resistivity region (less than $20 \Omega \mathrm{m}$ ) and the extremely low resistivity region (less than $3 \Omega \mathrm{m}$ ) are shown by the slightly gray and the darker portions, respectively.

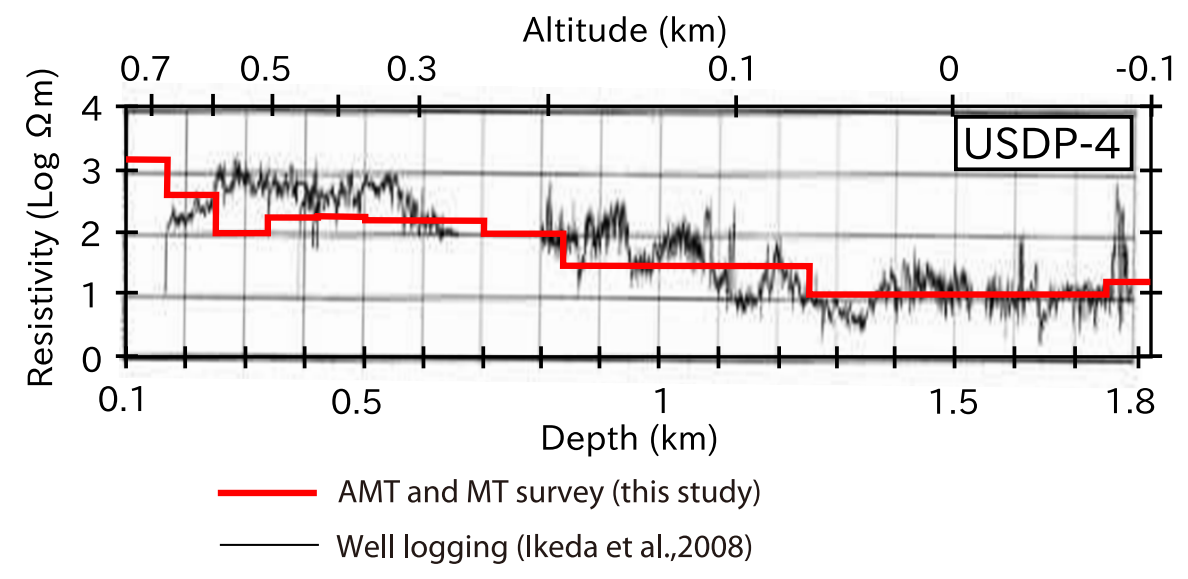

Fig. 7. Resistivities along the borehole USDP-4. Red and black lines represent the resistivities obtained by this study and those obtained by well logging (Ikeda et al., 2008), respectively.

length of observation time (about one week).

The sensitivity obtained in this analysis is a measure of the confidence that can be placed in the model. Therefore, it is necessary to determine the minimum sensitivity to constrain the reliable domain of the model. In order to determine the minimum reliable sensitivity, the southern deeper area with low sensitivities was used for the following further sensitivity analysis.

2.4.2 Determination of minimum reliable sensitivity The further analysis examines the change of sounding curves by distinctively changing the model. The southern deeper part contains two regions as shown by the region $\mathrm{X}$ and $\mathrm{Y}$ in Fig. 4. Resistivities of the region $\mathrm{X}$ is higher than those of the upper layer, in contrast to those of the region $\mathrm{Y}$, which shows resistivities that are lower than the upper layer. In this analysis, the resistivities of those regions were oppositely revised, and the fit of the changed soundings to the observed data was examined.

Case1: region $X$ Region $X$ has a high resistivity of more than $100 \Omega \mathrm{m}$. In this case, the sensitivity of TM phase of UZ399 was examined by replacing the region X with a $1 \Omega \mathrm{m}$ body in Case $1-1$, and by replacing a lower part of the region with a $1 \Omega \mathrm{m}$ body in Case $1-2$, respectively. Figure 5(b-1) shows the sensitivity of the phase of UZ399 in both cases. In Case1-1, the calculated sounding curve does not fit well between 3-10 Hz. On the other hand, in 
Case1-2, fit of the calculated sounding curve to observed data between $3-10 \mathrm{~Hz}$ is almost the same as that of the best-fit model, and both the sounding curves of Case1-2 and best-fit model can explain the data around $2 \mathrm{~Hz}$. It appears that the observed soundings cannot constrain the resistivity structure of region $\mathrm{X}$ at depths deeper than those defined by Case1-2.

Case2: region $\mathbf{Y}$ A low resistivity (below $10 \Omega \mathrm{m}$ ) extends from depths deeper than $1 \mathrm{~km}$ beneath UZ398. The sensitivity of TM phase of UZ398 was examined by replacing the region $\mathrm{Y}$ with a $100 \Omega \mathrm{m}$ body in Case2-1, and by replacing the lower part of the region with a 100 $\Omega \mathrm{m}$ in Case $2-2$, respectively.

Figure 5(b-2) shows the sensitivity of the phase of UZ398 in both cases. In Case2-1, the calculated sounding curve does not fit well between 15-3 Hz. In Case2-2, the difference of phase between Case2-2 and best fit model is within the margin of error. It appears that the observed soundings cannot constrain the resistivity structure of region $\mathrm{Y}$ at depths deeper than those defined by Case2-2.

The sensitivity tests described above correspond roughly to sensitivities less than $1.3 \times 10^{-5}$. Therefore, in this study, the model blocks with the sensitivities above $1.3 \times 10^{-5}$ were regarded as reliable.

\section{$2.5 \quad 2-D$ resistivity structure}

Figure 6(a) shows the resistivity structure of Unzen volcano after removing the low sensitivity regions. The surface is covered by the high resistivity (several to $10 \mathrm{k} \Omega \mathrm{m}$ ) layer with a thickness of several hundreds meters. This structure is in good agreement with the surface structure inferred from the airborne electromagnetic survey conducted by Mogi et al. (1995). Resistivity structure shifts from low to high at the depth of $2.5 \mathrm{~km}$. This feature is consistent with the previous works by Kagiyama et al. (1999) and Srigutomo et al. (2008).

Figure 7 shows the resistivities along the borehole USDP-4, where conduit drilling was performed (Nakada et al., 2005). Red and black lines represent the resistivities obtained by this study and those obtained by well logging (Ikeda et al., 2008). Well logging shows that resistivities gradually decrease from $1000 \Omega \mathrm{m}$ to $10 \Omega \mathrm{m}$ with depth. This trend of resistivities is well reproduced by this study. The resistivities at depths between 1.25 and $1.75 \mathrm{~km}$ inferred in this study are about $10 \Omega \mathrm{m}$, and similar to those obtained from well logging. Further, the increasing resistivities below $1.75 \mathrm{~km}$ depth also correspond well to those found in the borehole logs. Taken together, the findings from borehole resistivity logging support the hypothesized resistivity structure presented in this study.

\section{Discussion}

3.1 Comprehensive features of the resistivity structure

Figure 6(b) shows the interpretation of the resistivity structure. The obtained resistivity structure is composed of 4 layers: the high resistivity surface (greater than $1000 \Omega \mathrm{m}$, I in the figure), the intermediate second layer (20- several hundreds $\Omega \mathrm{m}$, II), the low resistivity third layer (less than $20 \Omega \mathrm{m}, \mathrm{III}$ ), and the relatively high resistivity layer beneath the third layer (IV).

We interpret the first layer as consisting of undersaturated lava and pyroclastic flow deposits. This interpretation is supported by the findings of Mogi et al. (1995), who used existing geological survey data to map the distribution of lava flows on Unzen volcano. Furthermore, Komori et al. (2010) pointed out that undersaturated pyroclastic flow deposits have a resistivity over $1000 \Omega \mathrm{m}$ by comparison between DC resistivity survey and resistivity measurements on the drillcore samples at the USDP-1 site on Unzen volcano; which is consistent with the conceptual model presented in this study.

The upper part of the intermediate second layer has a resistivity of several hundreds $\Omega \mathrm{m}$. It is present below the undersaturated lava and pyroclastic flow deposits, and also emerges on the surface of their northern and southern edges. Its emergence on the surface corresponds to the location of the cold springs, as shown in Fig. 6(b) (Research group of the groundwater for agricultural use, 1986). Komori et al. (2010), in their study of the USDP-1 core, found that the pyroclastic and mudflow deposits that comprise the host rock demonstrated resistivities on the order of several hundred $\Omega \mathrm{m}$ when saturated with low-salinity (several tens of $\Omega \mathrm{m}$ ) pore water, which is equivalent to the groundwater salinity of Unzen. On this basis, we conclude there is a water saturated aquifer extending downward through the several hundred $\Omega \mathrm{m}$ region, and that the cold water springs are a manifestation of groundwater discharge in this region.

The low resistivity third layer less than $20 \Omega$ m overlays the relatively high resistivity fourth layer. Yano et al. (1989) found that the effective porosities decrease to less than a few percent at the $2-3 \mathrm{~km}$ depth, using the drillcores obtained from volcanic and geothermal areas in Japan. This suggests that formations deeper than the depth can hold little water because of a lack of pores. Therefore, the relatively high resistivities deeper than $2 \mathrm{~km}$ below sea level (b.s.l.) are considered to be due to a lack of interstitial water in the bulk formation. It is estimated that the aquifer extends from the second layer through the third layer.

\subsection{Resistivity of the deeper aquifer}

Basically, the resistivity of the water-saturated aquifer is decreased with depth, and the low resistivity third layer extends downward to $2 \mathrm{~km}$ b.s.l. Decreasing resistivities are considered to be due to the increase of fluid salinity and/or rock alteration (e.g., Keller and Rapolla, 1974; Revil et al., 2002). On the other hand, regarding the deeper region of the summit area, the region with a resistivity of 20 $80 \Omega \mathrm{m}$ extends upward to $0.5 \mathrm{~km}$ b.s.l., as indicated by $\mathrm{R}$ in Fig. 6(b). Further, this region is surrounded by the extremely low resistivity region less than $3 \Omega \mathrm{m}(\mathrm{C} 1$ and $\mathrm{C} 2$ in Fig. 6(b)).

The resistivity structure described in the preceding paragraph is typical for an active volcano (e.g., Usu volcano (Ogawa et al., 1998; Matsushima et al., 2001); Galunggung Volcano (Wannamaker et al., 2004); Kusatsu-shirane volcano (Nurhasan et al., 2006); Asama volcano (Aizawa et al., 2008); Aso volcano (Kanda et al., 2008); Rotokawa geothermal field (Heise et al., 2008)). In general, such an extremely low resistivity is interpreted as low permeability clay due to hydrothermal alteration (e.g., Ogawa et al., 1998; Revil et al., 2002); it is believed that low permeability clay behaves as a sealing zone, and that high temperature 
fluids are maintained and circulate within the relatively high resistivity region (e.g., Björnsson et al., 1986; Ussher et al., 2000). The relatively high resistivity of the fluid-bearing zone is considered to be due to undersaturation by a gas phase, and/or the breakdown of conductive smectite by high temperature conditions (Pytte and Reynolds, 1989).

In Unzen volcano, a temperature of $180^{\circ} \mathrm{C}$ was estimated at the bottom of the borehole USDP-4 from temperature logging and fluid inclusion studies (Nakada et al., 2005). Furthermore, geodetic surveys found the pressure source during the 1990-1995 eruption at a depth of about 1.5-3 $\mathrm{km}$ beneath the summit (Geodetic Survey Group, Joint Observation by National Universities, 1991; Ishihara, 1993; Hendrasto et al., 1997; Kohno et al., 2008). These facts suggest that the condition of higher temperature is maintained by the shallowly-emplaced dikes inside the region. Therefore, a typical hydrothermal system may be present in the deeper part of the aquifer beneath Unzen volcano, which would explain the absence of a high conductance region at the summit noted by Srigutomo et al. (2008).

Fujimitsu et al. (2008) performed numerical simulations to investigate the hydrothermal system at whole Shimabara Peninsula, by assuming the heat source in the western deeper part of the Peninsula. Their work does not consider the heat source beneath the summit area of Unzen volcano, because of the assumed small contribution from the pressure source to crustal deformation during eruption. In contrast to their assumption, the hydrothermal system inferred in the present study may make a non-negligible contribution to the heat and mass transfer of the whole magmatic system of the Shimabara Peninsula.

\section{Conclusions}

This study provides the spatially detailed look at the 2-D resistivity structure of Unzen volcano in southeast Japan by AMT and MT surveys, considering the regional dimensionality of the area. Unzen volcano is shown to consist of 4 resistivity layers. The high resistivity first layer is considered to be undersaturated lava and pyroclastic flow deposits. A water-saturated aquifer is inferred to extend from the intermediate second layer to the low resistivity third layer. Within the deeper part of the summit area, the data show a region of resistivity on the order of $20-80$ ohm-m, surrounded by an extremely low resistivity region of less than 3 ohm-m. Although similar features are typical for active volcanoes, such the resistivity structure has not previously been known to exist at Unzen volcano. By analogy with other active volcanic systems, we hypothesize this low resistivity region results from the existence of a hydrothermal system comprising high-temperature volcanic fluids beneath the summit area. If so, the hypothesized hydrothermal system could make a non-negligible contribution to the heat and mass transfer of the regional magmatic system of the Shimabara Peninsula. As a result of the potential regional importance of such a system, we recommend additional investigations to characterize and more clearly delineate this intriguing feature.

Acknowledgments. We thank H. Shimizu for arranging observation schedule, and Nittetsu Mining Consultants Co., Ltd. and
Geospatial Information Authority of Japan for providing the geomagnetic data at Kagoshima and Sawauchi. We thank N. Oshiman and R. Yoshimura for their valuable discussion, and J. P. Fairley for improving our manuscript. The manuscript was critically reviewed by two anonymous reviewers. We are grateful for the editorial support of M. Uyeshima. This work was supported by the Grant-in-Aid for Scientific Research (No. 19310116 and No. 23310120, T. Kagiyama) from the Ministry of Education, Culture, Sports, Science and Technology, Japan. Some figures were made using the GMT program (Wessel and Smith, 1998).

\section{References}

Aizawa, K., Y. Ogawa, T. Hashimoto, T. Koyama, W. Kanda, Y. Yamaya, M. Mishina, and T. Kagiyama, Shallow resistivity structure of Asama Volcano and its implications for magma ascent process in the 2004 eruption, J. Volcanol. Geotherm. Res., 173, 165-177, doi:10.1016/j.jvolgeores.2008.01.016, 2008.

Bibby, H. M., T. G. Caldwell, and C. Brown, Determinable and non-determinable parameters of galvanic distortion in magnetotellurics, Geophys. J. Int., 163, 915-930, doi:10.1111/j.1365246X.2005.02779.x, 2005.

Björnsson, A., G. P. Hersir, and G. Björnsson, The Hengill hightemperature area, S.W. Iceland: Regional geophysical survey, Geotherm. Resour. Counc. Trans., 10, 205-210, 1986.

Cagniard, L., Basic theory of the magnetotelluric method of geophysical prospecting, Geophysics, 18, 605-645, 1953.

Caldwell, T. G., H. M. Bibby, and C. Brown, The magnetotelluric phase tensor, Geophys. J. Int., 158, 457-469, doi:10.1111/j.1365246X.2004.02281.x, 2004.

Chida, N., Late Quaternary tectonic movements in central Kyushu district, Southwest Japan, with special reference to the active faults distributed in the Quaternary volcanic area, Ann. Rep. Fac. Educ., Iwate Univ., 39, 97-135, 1979.

Fujimitsu, Y., S. Ehara, R. Oki, and R. Kanou, Numerical model of the hydrothermal system beneath Unzen Volcano, Japan, J. Volcanol. Geotherm. Res., 175, 35-44, 2008.

Gamble, T. D., W. M. Goubau, and J. Clarke, Magnetotellurics with a remote magnetic reference, Geophysics, 44, 53-68, doi:10.1190/1.1440923, 1979.

Geodetic Survey Group, Joint Observation by National Universities, Ground deformation of Unzen Volcano accompanied by the volcanic activity, Observational Studies on Unzen Volcano Regarding the Prediction of Lava Effusion, 29-42, 1991.

Hashimoto, T., Self-potential changes and subsurface hydrothermal activity accompanying the 1900-1995 eruption of Unzen volcano, J. Geomag. Geoelectr., 49, 966-993, 1997.

Hashimoto, T. and Y. Tanaka, A large self-potential anomaly on Unzen Volcano, Shimabara Peninsula, Kyushu island, Japan, Geophys. Lett. Res., 22, 191-194, 1995.

Heise, W., T. G. Caldwell, H. M. Bibby, and S. C. Bannister, Threedimensional modelling of magnetotelluric data from the Rotokawa geothermal field, Taupo Volcanic Zone, New Zealand, Geophys. J. Int., 173, 740-750, 2008.

Hendrasto, M., T. Eto, F. Kimata, T. Matsushima, and K. Ishihara, Magma transport at Mt. Unzen associated with the 1990-1995 activity inferred from leveling data, Ann. Disas. Prev. Res. Inst. Kyoto Univ., 40(B-1), 61-72, 1997.

Hoshizumi, H., K. Uto, and K. Watanabe, Geology and eruptive history of Unzen volcano, Shimabara Peninsula, Kyushu, SW Japan, J. Volcanol. Geotherm. Res., 89(1-4), 81-94, doi:10.1016/S0377-0273(98)00125-5, 1999.

Hoshizumi, H., K. Uto, A. Matsumoto, S. Xu, and K. Oguri, Geology of Unzen volcano and core stratigraphy of the flank drillings, Extended Abstract of International Unzen Workshop, 4-7, 2002.

Ikeda, R., T. Kajiwara, K. Omura, and S. Hickman, Physical rock properties in and around a conduit zone by well-logging in the Unzen Scientific Drilling Project, Japan, J. Volcanol. Geotherm. Res., 175, 13-19, doi:10.1016/j.jvolgeores.2008.03.036, 2008.

Ishihara, K., Continuous magma supply inferred from discharge rate of magma and ground-deformation rate at Mt. Unzen, Japan, Ann. Disas. Prev. Res. Inst., Kyoto Univ., 36(B1), 219-230, 1993.

Jiracek, G. R., Near-surface and topographic distortions in electromagnetic induction, Surv. Geophys., 11, 162-203, 1990.

Kagiyama, T., H. Utada, and T. Yamamoto, Magma ascent beneath 
Unzen Volcano, SW Japan, deduced from the electrical resistivity structure, J. Volcanol. Geotherm. Res., 89, 35-42, doi:10.1016/S03770273(98)00120-6, 1999.

Kanda, W., On a deep transient electromagnetic sounding-measurement and modeling, Ph.D Thesis, The University of Tokyo, Japan, 1997.

Kanda, W., Y. Tanaka, M. Utsugi, S. Takakura, T. Hashimoto, and $\mathrm{H}$. Inoue, A preparation zone for volcanic explosions beneath Naka-dake crater, Aso volcano, as inferred from magnetotelluric surveys, J. Volcanol. Geotherm. Res., 178, 32-45, doi:10.1016/j.jvolgeores.2008.01.022, 2008.

Keller, G. V. and A. Rapolla, Electrical prospecting methods in volcanic and geothermal environments, in Physical Volcanology, edited by L. Civetta, P. Gasparini, G. Luongo, and A. Rapolla, pp. 133-166, Elsevier, Amsterdam, 1974.

Kohno, Y., T. Matsushima, and H. Shimizu, Pressure sources beneath Unzen Volcano inferred from leveling and GPS data, J. Volcanol. Geotherm. Res., 175, 100-109, doi:10.1016/j.jvolgeores.2008.03.022, 2008.

Komori, S., T. Kagiyama, H. Hoshizumi, S. Takakura, and M. Mimura, Vertical mapping of hydrothermal fluids and alteration from bulk conductivity: Simple interpretation on the USDP-1 site, Unzen Volcano, SW Japan, J. Volcanol. Geotherm. Res., 198, 339-347, doi:10.1016/j.jvolgeores.2010.09.019, 2010.

Matsushima, N., H. Oshima, Y. Ogawa, S. Takakura, H. Satoh, M. Utsugi, and Y. Nishida, Magma prospecting in Usu volcano, Hokkaido, Japan, using magnetotelluric soundings, J. Volcanol. Geotherm. Res., 109, 263-277, 2001.

Mogi, T., Y. Tanaka, T. Morikawa, K. Kusakabe, M. Tanahashi, T. Nakatsuka, K. Tanaka, and H. Utada, Subsurface structure of UnzenFugen and Mayu-yama volcano inferred from airborne electromagnetic method and magnetic survey, Bull. Volcanol. Soc. Jpn., 40, 263-276, 1995.

Nakada, S., K. Uto, S. Sakuma, J. C. Eichelberger, and H. Shiimizu, Scientific results of conduit drilling in the Unzen Scientific Drilling Project (USDP), Science Drilling, no. 1, 18-22, doi:10.2204/iodp.sd.1.03.2005, 2005.

Nurhasan, Y. Ogawa, N. Ujihara, S. B. Tank, Y. Honkura, S. Onizawa, T. Mori, and M. Makino, Two electrical conductors beneath KusatsuShirane volcano, Japan, imaged by audiomagnetotellurics, and their implications for the hydrothermal system, Earth Planets Space, 58, 1053-1059, 2006.

Ogawa, Y. and T. Uchida, A two-dimensional magnetotelluric inversion assuming Gaussian static shift, Geophys. J. Int., 126, 69-76, doi:10.1111/j.1365-246X.1996.tb05267.x, 1996.

Ogawa, Y., N. Matsushima, H. Oshima, S. Takakura, M. Utsugi, K. Hirano, M. Igarashi, and T. Doi, A resistivity cross-section of Usu volcano, Hokkaido, Japan, by audiomagnetotellurics soundings, Earth Planets Space, 50, 339-346, 1998.

Ohta, K., A study of hot springs on the Shimabara Peninsula, The Science Reports of the Shimabara Volcano Observatory, the Faculty of Science,
Kyushu University, 8, 1-33, 1973.

Pytte, A. M. and R. C. Reynolds, The Thermal Transformation of Smectite to Illite, in Thermal History of Sedimentary Basins: Methods and Case Histories, 319 pp., Springer-Verlag, New York, 1989.

Research group of the groundwater for agricultural use, Groundwater of Japan, 1043 pp., Tikyusha, Japan, 1986.

Revil, A., D. Hermitte, E. Spangenberg, and J. J. Cochemé, Electrical properties of zeolitized volcaniclastic materials, J. Geophys. Res., 107(B8), doi:10.1029/2001JB000599, 2002.

Schwalenberg, K., V. Rath, and V. Haak, Sensitivity studies applied to a two-dimensional resistivity model from the Central Andes, Geophys. $J$. Int., 150, 673-686, 2002.

Simpson, F. and K. Bahr, Practical Magnetotellurics, 254 pp., Cambridge University Press, Cambridge, 2005.

Srigutomo, W., T. Kagiyama, W. Kanda, H. Munekane, T. Hashimoto, Y. Tanaka, H. Utada, and M. Utsugi, Resistivity structure of Unzen Volcano derived from time domain electromagnetic (TDEM) survey, J. Volcanol. Geotherm. Res., 175, 231-240, doi:10.1016/j.jvolgeores.2008.03.033, 2008.

Takahashi, H., K. Kazahaya, H. Shinohara, and T. Nakamura, Pathways for escape of magmatic carbon dioxide to soil air at Unzen Volcano, SW Japan, Radiocarbon, 46, 491-496, 2004.

Umakoshi, K., H. Shimizu, and N. Matsuwo, Magma ascent path in the 1990-1994 eruption of Fugendake, Unzen volcano, as inferred from precisely determined hypocentral distribution, Bull. Volcanol. Soc. Jpn., 39, 223-235, 1994.

Ussher, G., C. Harvey, R. Johnstone, and E. Anderson, Understanding resistivities observed in Geothermal Systems, in Proceedings World Geothermal Congress 2000, Kyushu-Tohoku, Japan, 2000.

Vozoff, K., The magnetotelluric method, in Electromagnetic Methods in Applied Geophysics, edited by M. N. Nabighian, 972 pp., Society of Exploration Geophysicists, USA, 1991.

Wannamaker, P. E., J. A. Stodt, and L. Rijof, Two-dimensional topographic responses in magnetotellurics modeled using finite elements, Geophysics, 51, 2131-2144, 1986.

Wannamaker, P. E., I. Raharjo, J. N. Moore, and R. Allis, Magnetotelluric resistivity section and physical implications through the Telaga Bodas magmatic geothermal system, Indonesia, Geotherm. Resour. Counc. Trans., 28, 369-371, 2004.

Wessel, P. and W. H. F. Smith, New, improved version of Generic Mapping Tools released, Eos Trans. AGU, 79(47), 579, 1998.

Yano, Y., Y. Suda, and S. Tamanyu, Well data compiled from Japanese nation-wide geothermal surveys, part 1 core sample data-physical properties, geology, age, chemical composition-, Rep. Geol. Surv. Jpn., 271, 832 pp., 1989.

S. Komori (e-mail: komori@earth.sinica.edu.tw), T. Kagiyama, M. Utsugi, H. Inoue, and I. Azuhata 